Joling, K.J., Hout, H.P.J. van, Schellevis, F.G., Horst, H.E. van der, Scheltens, P., Marwijk, H.W.J. van.Jncideln of depression and anxiety in the spouses of patients with dementia: a naturalistic cohort study of recorded morbidity with a 6-year follow-up. American Journal of Geriatric Psychiatry: 2010, 18(2), 146-153

\begin{tabular}{|c|c|}
\hline $\begin{array}{l}\text { Postprint } \\
\text { Version }\end{array}$ & 1.0 \\
\hline Journal website & $\begin{array}{l}\text { http://journals.lww.com/ajgponline/Abstract/2010/02000/Incidence_of_Depress } \\
\text { ion and Anxiety in the Spouses.7.aspx }\end{array}$ \\
\hline Pubmed link & http://www.ncbi.nlm.nih.gov/pubmed/20104070 \\
\hline DOI & 10.1097/JGP.0b013e3181bf9f0f \\
\hline
\end{tabular}

This is a NIVEL certified Post Print, more info at http://www.nivel.eu

\title{
Incidence of Depression and Anxiety in the Spouses of Patients With Dementia: A Naturalistic Cohort Study of Recorded Morbidity With a 6-Year Follow-Up
}

Joling, Karlijn J. MS.C.; VAn Hout, Hein P.J. Ph.D.; SchelleVis, Francois G. M.D., Ph.D.; VAN DER Horst, Henriette E. M.D., Ph.D.; Scheltens, PhiliP M.D., Ph.D.; KNOL, DiRK L. Ph.D.; VAN MARWIJK, HARM W.J. M.D., PH.D.

Author Information

From the Department of General Practice, Institute for Research in Extramural Medicine (KJJ, HPJvH, FGS, HEvdH, HWJvM); Department of Neurology, Alzheimer Centre (PS), VU University Medical Centre, Amsterdam; NIVEL (Netherlands Institute for Health Services Research), Utrecht (FGS); and Department of Epidemiology and Biostatistics, VU University Medical Centre, Amsterdam (DLK), The Netherlands. Send correspondence and reprint requests to Karlijn Joling, MS.c., Department of General Practice, Institute for Research in Extramural Medicine, VU University Medical Centre, Van der Boechorststraat 7, 1081 BT, Amsterdam, The Netherlands. e-mail: k.joling@vumc.nl

\begin{abstract}
Objective: Living with a demented person has been associated with high levels of clinical depression and anxiety. However, there are no prospective studies that allow good estimates of the incidence of depression and anxiety. In this study, the authors assess the long-term incidence of depression and anxiety in the spouses of patients with dementia as recorded by general practitioners. Design: Prospective naturalistic cohort study with a comparison group. Data from medical records in 2001-2007 were analyzed. Participants: Two hundred eighteen spouses of patients with dementia and 353 age and gender-matched spouses of non demented persons. Setting: Seventy-one general practices in the Netherlands with a listed source population of 320,309 patients. Measurements: Incidence rates (IRs) per 1,000 person-years and hazard ratios (HRs) of depression and anxiety; prescription rates (per 1,000 person-years) for antidepressants and anxiolytics. Results: A new episode of depression was diagnosed in 18 spouses and 7 comparison spouses (IRs of 18.8/1,000 person-years and 4.4/1,000 person-years, respectively). Spouses of patients with dementia were far more likely to be diagnosed with depression than the comparison spouses (HR, 4.16; 95\% CI: 1.73-9.98). Spouses did not have a higher incidence of anxiety than the comparison group (HR, 1.26; 95\% CI: 0.58-2.71). The prescription rates for both antidepressants and anxiolytics were significantly higher for spouses than for the comparison group. Conclusion: The spouses of patients with dementia have a fourfold higher risk of a diagnosis of depression than the spouses of nondemented persons.
\end{abstract}


Dementia is a highly prevalent disorder in the elderly, and with the aging of the population, the number of dementia patients will increase considerably in the next few decades.1,2 The majority of these patients live in the community. Often a family member cares for them, and if a spouse is present, he or she usually acts as the primary informal caregiver.3 Taking care of a relative with dementia is burdensome and can lead to health problems, especially mental health problems.4,5 Numerous studies have reported that the prevalence of depression and anxiety in caregivers is high.6-11 However, very little is known about the incidence rates (IRs) for anxiety and depression in the spouses of patients with dementia. Very few studies, all small scale and with selected populations, have reported such IR.

Tackling psychiatric morbidity in caregivers is needed to reduce their distress and enable them to continue caring for their family member. Poor health of the primary caregiver is a major predictor for institutionalization of the patient.12 When a caregiver is no longer able to handle the daily care for the demented person, an appeal will be made for professional care, with potentially high costs for society. Therefore, the timely detection of (subthreshold) psychiatric morbidity in spousal caregivers combined with appropriate interventions is extremely important and may be very cost-effective.

Incidence studies are needed to further assess the risks for the occurrence of psychiatric disorders. More precise estimates of the incidence of depression and anxiety in the caregiver population will enable us to assess the need for healthcare services and the need to provide support for this specific group more adequately.

Good-quality prospective studies on the incidence of depression in caregivers are rare, and the few that have been carried out mainly describe the prevalence or correlates of psychiatric morbidity.6,4,13,14 In a systematic review, Cuijpers 9 reported that nearly half of the caregivers of dementia patients develop depression. However, this estimate was based on three studies, only one of which reported an IR.15 The other two studies did not report IRs for subjects who did not have a depressive disorder at baseline.16,17 In one study, $25 \%$ of the caregivers met the criteria for a depressive disorder at baseline, when compared with $32 \%$ after 13 months. 16 In the other study, 4 years after baseline, $34 \%$ of the caregivers had had a depressive disorder, when compared to $17 \%$ at baseline. 17

The manifestation of anxiety among family caregivers of patients with dementia has received even less attention.11,18 Theoretically, anxiety is likely to occur as a consequence of the distress caused by the caregiving situation. A systematic review reported that clinically significant anxiety affects about a quarter of caregivers for people with dementia and was more common than in matched controls. 11 Nevertheless, no cohort studies have yet focused on the incidence of anxiety in family caregivers.

In this article, we address the following research question: what is the incidence of depression and anxiety as recorded in general practice among the spouses of patients with dementia, compared with age and gender matched spouses of nondemented persons?

We hypothesized that the spouses of patients with dementia are more frequently diagnosed with depression and anxiety than the comparison spouses and that this will also be reflected in higher prescription rates for antidepressants and anxiolytics and referral rates to specialist mental healthcare among the spouses of patients with dementia.

\section{METHODS}

The incidences found in this study are based on continuous recordings of diagnoses by specifically trained general practitioners (GP). Unlike most other researchers, we could make use of data from an unselected population with a very long follow-up period of 6 years. In the Netherlands, the GP acts as the "gatekeeper" to specialist care. All inhabitants are registered in a general practice, and $90 \%$ of the elderly visit their GP at least once a year. 19 Therefore, the morbidity reported in general practice is representative for the morbidity reported in healthcare in general.

\section{Design and Study Population}

In this prospective cohort study, we compared the spouses of patients with dementia with matched spouses of nondemented persons to assess the incidence of depression and anxiety, the prescription of antidepressants, and referrals to mental healthcare specialists from 2001 to 2007. The incidences are based 
Joling, K.J., Hout, H.P.J. van, Schellevis, F.G., Horst, H.E. van der, Scheltens, P., Marwijk, H.W.J. van_lncidrence of depression and anxiety in the spouses of patients with dementia: a naturalistic cohort study of recortated morbidity with a 6-year follow-up. American Journal of Geriatric Psychiatry: 2010, 18(2), 146-153

on continuous registrations in medical records made by GPs who had been specifically trained in diagnostic coding.

\section{Data Collection}

\section{Practices and Source Population.}

Data were retrieved from the routinely kept electronic medical records of patients registered in general practices participating in the Netherlands General Practice Information Network (LINH). The LINH database holds longitudinal data on approximately 340,000 individuals, collected by a nationally representative network of $180 \mathrm{GPs}$, spread throughout the Netherlands. Since 2001, these GPs have been continuously recording data on the number of consultations, diagnoses, prescriptions, and referrals in the electronic medical records of all their registered patients. Contact diagnoses were clustered into episodes of the same disease.20-22 For each episode, the GPs recorded whether it concerned a first visit or a follow-up visit. The GPs were trained to code according to the International Classification of Primary Care (ICPC). A written manual and a desk card with all ICPC-codes with short definitions were provided to them. Before their participation in LINH, the GPs completed a course in the use of the ICPC as well. Furthermore, the registration system of the participating general practices was adjusted to support the ICPC coding. The adjusted registration systems checked for missing data and reminded the GP to code a diagnosis. The GPs could also use a thesaurus of keywords, which made it easier to search for the correct ICPC code. To determine the variability in coding between GPs they were asked to code 30 written case vignettes (nonresponse 17\%). Their codes were compared with an expert panel of four nonparticipating GPs with specific expertise in the ICPC. The average consensus between the GPs and (at least one of) the experts was $81 \% .23$

\section{Spouses of Patients With Dementia.}

From the database, we selected all spouses of patients who received a diagnosis of dementia during 2001 $(\mathrm{N}=218)$. Spouses who, themselves, were also diagnosed with dementia in 2001-2007 were excluded $(\mathrm{N}=$ 17).

\section{Comparison Spouses.}

For every spouse of a demented patient, an independent researcher selected, if available, two comparison spouses from the same practice, matched for age in 5-year intervals, gender, and living with a spouse $(\mathrm{N}=$ 353). If more than two comparison spouses were available, a random selection was performed. Neither the comparison spouses nor their partners were diagnosed with dementia during the study period. The entry date of spouses and comparison spouses was set as the date on which the patient for whom the spouse was caring was diagnosed with dementia.

\section{Outcome Measures}

The main outcome measures were the IRs for depression and anxiety. Because drop out could occur during follow-up, we calculated annual IRs per 1,000 persons. We calculated the hazard ratio (HR) adjusted for age, gender, and number of chronic diseases. The secondary outcome measures were prescription rates for antidepressants and the number of referrals to specialist mental healthcare.

\section{Definition and Computation of Incidence.}

The main outcome measures were the IRs for depression and anxiety. Because drop out could occur during follow-up, we calculated annual IRs per 1,000 persons. We calculated the hazard ratio (HR) adjusted for age, gender, and number of chronic diseases. The secondary outcome measures were prescription rates for antidepressants and the number of referrals to specialist mental healthcare.

\section{Main Outcome Measures}

- Depression: a new episode of depressive feelings (ICPC-code P03) or depression disorder (P76). The diagnostic criteria for depressive depression disorder are based on Diagnostic and Statistical Manual of Mental Disorders, Fourth Edition, criteria for major depression. Depressive feeling is comparable with minor depression. 
Joling, K.J., Hout, H.P.J. van, Schellevis, F.G., Horst, H.E. van der, Scheltens, P., Marwijk, H.W.J. van_lncidrence of depression and anxiety in the spouses of patients with dementia: a naturalistic cohort study of recorated morbidity with a 6-year follow-up. American Journal of Geriatric Psychiatry: 2010, 18(2), 146-153

- Anxiety: a new episode of anxious feelings (P01) or anxiety disorder (P74). The diagnostic criteria for anxiety disorder are comparable with Diagnostic and Statistical Manual of Mental Disorders, Fourth Edition, anxiety disorders. Anxious feeling is comparable with subthreshold anxiety.

\section{Secondary Outcome Measures}

Prescription of antidepressants and anxiolytics: prescriptions for medication were coded according to the Anatomical Therapeutic Chemical Classification System. We calculated the annual prescription rate for antidepressants (Anatomical Therapeutic Chemical Classification system codes listed under N06A) and anxiolytics (N05B) per 1,000 persons.

Referrals to specialist mental healthcare: number of spouses and comparison spouses referred to mental healthcare (psychologist, psychiatry, mental healthcare center, and psychotherapy) after the spouse's partner was diagnosed with dementia.

\section{Statistical Analysis}

Among spouses and comparison spouses, IRs of depression and IRs of anxiety per 1,000 person-years were calculated. Because spouses and comparison spouses could leave the practice before the end of the study period, we corrected for the period during which the person was registered when calculating the IRs. Spouses of patients with dementia were matched with spouses of nondemented patients. Therefore, the analyses were performed using techniques to adjust for the correlation between the spouses and comparison spouses. The measures for each spouse and their matched comparison spouse(s) are treated as a cluster. Depression and anxiety-free survival of spouses and comparison spouses were compared using a shared gamma frailty model (a random-effects model). A frailty model is a random-effects model for time variables, where the random effect (the frailty) has a multiplicative effect on the hazard.24 The analyses included adjustment for differences in age (as a continuous variable), sex, and number of chronic diseases within the first year after entering the study. The number of chronic diseases was based on the Statistics the Netherlands list of chronic diseases.25 We measured time to event from the date of onset of dementia in the patient. Persons who were episode-free during the entire follow-up period were censored on December 31, 2006, for these analyses. Persons who dropped out of the cohort (e.g., due to moving house) were censored on the drop-out date. Persons whose drop-out date was unknown were censored on the date of the last known visit to the practice.

Differences in the number of spouses and comparison spouses receiving an antidepressant or anxiolytic prescription were evaluated with a logistic regression model using the generalized estimating equation method. Analyses were performed with SPSS (version 15.0) and Stata (version 10.1) statistical packages. Statistical significance was considered as two-tailed $\mathrm{p}<0.05$.

\section{RESULTS}

\section{Study Population}

Data were extracted from 71 general practices that participated in LINH from 2001 to 2007. In 2001, 218 patients were diagnosed with dementia and were living with a spouse. The mean age of the patients with dementia was 78 years (range: $55-98$ ), and $60 \%$ of them were men.

\section{Spouses of a Patients With Dementia: Exposed Spouses.}

\section{[TABLE 1 AND FIGURE 1]}

For the 218 spouses of a demented person, the mean follow-up period was 4.78 years. The spouses had a mean age of 76.2 years (range: 54-93, SD 7.3) and were mainly women. The other characteristics of the spouses are shown in Table 1. Of these spouses, 29\% died or left the practice for different reasons before the end of the study period (Fig. 1). During the follow-up period, 10 spouses (4\%) did not visit their GP at all.

\section{Comparison Spouses.}


Joling, K.J., Hout, H.P.J. van, Schellevis, F.G., Horst, H.E. van der, Scheltens, P., Marwijk, H.W.J. van.Incidennce of depression and anxiety in the spouses of patients with dementia: a naturalistic cohort study of recorded morbidity with a 6-year follow-up. American Journal of Geriatric Psychiatry: 2010, 18(2), 146-153

The total population of matched comparison spouses consisted of 353 persons. For 159 spouses of patients with dementia, we found two matched comparison spouses; for 35 spouses, we found one matched comparison spouse; and for 22 spouses, no matched comparison spouse could be found. The mean followup period for the comparison spouses was 4.67 years. Their mean age was 75.3 years (range: 52-93, SD 7.4). The other characteristics of the comparison group are presented in Table 1. Of the comparison spouses, $31 \%$ died or left the practice for different reasons before the end of the study period (Fig. 1). During the follow-up period, 27 comparison spouses (8\%) did not visit their GP at all. The characteristics of the spouses and the comparison spouses are presented in Table 1.

\section{Depression}

\section{[TABLE 2]}

During the study period, six spouses and six comparison spouses consulted their GP because of having a prevalent depression. These persons were excluded to calculate the incidence of depression. In $8 \%$ of the spouses with a demented partner, the GP recorded incident depression. The majority had a depressive disorder, and the others had a minor depression (Table 2). The mean time to the new episode of depression was 22 months. Of the depressed spouses, 11 had a demented partner who died during the study period. Most of these spouses 7 had their first episode of depression after the death of their partner, and this occurred, on average 7 months after their partner's death. None of the 18 depressed spouses had a partner who was institutionalized during the follow-up period. Only $2 \%$ of the comparison spouses had incident depression. Most of them had a depressive disorder, and a minority had a minor depression (Table 2). This occurred after a mean period of 1.5 years.

The IR for depression was 18.8/1,000 person-years for spouses and 4.4/1,000 person-years for comparison spouses. Cox regression analysis using a random effects model showed that the spouses were far more likely to have a new episode of depression than the comparison spouses during the follow-up period (HR, 4.16; $95 \%$ CI: $1.73-9.98 ; z=3.19$, and $p=0.001)$. This risk was even higher for depression at disorder level only (ICPC-code P76) for the spouses than for the comparison spouses. When analyzing only the period that the demented person was alive, the spouses were still three times more likely to get a diagnosis of incident depression than comparison spouses (HR, 2.98; 95\% CI: 1.15-7.71; $z=2.26, p=0.024$ ).

\section{Anxiety}

During the study period, six spouses and seven comparison spouses consulted their GP because of having prevalent anxiety. These persons were excluded to calculate the incidence of anxiety. A new episode of anxiety was diagnosed in $6 \%$ of the spouses (Table 2). Anxiety was diagnosed for the first time after a mean period of 1.7 years. Of the spouses with anxiety, six had a demented partner who died during the study period; none of the patients with dementia they cared for were institutionalized. All but one of the spouses had their first episode of anxiety after the death of their partner, and this occurred, on average, 20 months after their partner's death. The GPs diagnosed a new episode anxiety in $4 \%$ of the comparison spouses (Table 2). They had an incident diagnosis of anxiety after a mean period of 16 months. For the spouses and for the comparison spouses, the majority with incident anxiety had a diagnosis of subthreshold anxiety, and only a few had an anxiety disorder.

The IR for anxiety was 12.4/1,000 person-years for spouses, and 9.5/1,000 person-years for comparison spouses. The time to diagnosis of anxiety did not differ significantly between both groups (HR, 1.26; $95 \%$ CI $0.58-2.71 ; z=0.58, p=0.561)$. There was no change in these findings when the analysis was repeated at disorder level (ICPC-code P74) only. When analyzing only the period that the demented person was alive, the HR decreased to 0.80 (95\% CI: $0.31-2.03 ; z=-0.47, p=0.635)$.

\section{Comorbidity of Depression and Anxiety}

Of all the spouses with incident depression, six (33\%) were also diagnosed with anxiety. Of these, three had a depression first, and three had anxiety first. There was only one spouse in the comparison group who had both depression and anxiety, and depression was diagnosed first in this person.

\section{Prescription of Antidepressants}

The number of spouses who received a prescription for antidepressants was significantly higher than the number of comparison spouses (Wald $[\mathrm{chi}]^{2}=11.8, d f=1, \mathrm{p}=0.001$ ). During the study period, the percentage of spouses who received at least one prescription for an antidepressant was about twice as high 
Joling, K.J., Hout, H.P.J. van, Schellevis, F.G., Horst, H.E. van der, Scheltens, P., Marwijk, H.W.J. van.Incidrence of depression and anxiety in the spouses of patients with dementia: a naturalistic cohort study of recorated morbidity with a 6-year follow-up. American Journal of Geriatric Psychiatry: 2010, 18(2), 146-153

as in percentage in the comparison group. This corresponds with a prescription rate of $36.5 / 1,000$ personyears and 17.0/1,000 person-years for spouses and comparison spouses, respectively. The absolute numbers of persons with an antidepressant prescription are presented in Table 2.

Antidepressants were prescribed for 16 of the 24 spouses with incident depression or anxiety. Furthermore, eight spouses with prevalent depression or anxiety received a prescription for an antidepressant. Antidepressants were prescribed for 14 persons, even though the GP did not record a diagnosis of depression or anxiety. There were 9 of the 21 comparison spouses with incident depression or anxiety and four comparison spouses with prevalent depression or anxiety who received a prescription for antidepressants. The GPs also prescribed antidepressants for 15 comparison spouses without recording a diagnosis of depression or anxiety.

Antidepressants were prescribed for 16 of the 24 spouses with incident depression or anxiety. Furthermore, eight spouses with prevalent depression or anxiety received a prescription for an antidepressant. Antidepressants were prescribed for 14 persons, even though the GP did not record a diagnosis of depression or anxiety. There were 9 of the 21 comparison spouses with incident depression or anxiety and four comparison spouses with prevalent depression or anxiety who received a prescription for antidepressants. The GPs also prescribed antidepressants for 15 comparison spouses without recording a diagnosis of depression or anxiety.

\section{Prescription of Anxiolytics}

Anxiolytics were more often prescribed for spouses than for comparison spouses (Wald $\chi^{2}=5.7, d f=1, \mathrm{p}$ $=0.017$ ). The prescription rates were 53.7/1,000 person-years and 37.6/1,000 person-years, respectively. The absolute number of persons in both groups with an anxiolytic prescription is presented in Table 2.

Of the 24 spouses with incident depression or anxiety, 19 received a prescription for an anxiolytic. The other anxiolytic prescriptions were for five spouses with prevalent depression or anxiety and 32 spouses for whom no such diagnosis was recorded. Anxiolytics were prescribed for 10 of the 21 comparison spouses with an incident depression or anxiety, for 7 comparison spouses with a prevalent episode, and for 45 comparison spouses for whom no such diagnosis was recorded. A number of spouses and comparison spouses received a prescription for both antidepressants and anxiolytics (Table 2).

\section{Referrals to Mental Healthcare}

During the study period, only four spouses and one spouse in the comparison group were referred to a mental healthcare specialist. Of the spouses who were referred, two were diagnosed with incident depression. Neither the other two spouses nor the spouse in the comparison group had a recorded diagnosis of anxiety or depression. Further analyses were inappropriate because these numbers were so small.

\section{DISCUSSION}

In this study, we found, as hypothesized, that the spouses of patients with dementia had a fourfold risk of diagnosis of incident depression, when compared with matched spouses of nondemented persons during an average follow-up of almost 5 years. Data concerning medication supported this finding. The spouses of patients with dementia had a twofold risk for the prescription of antidepressants. However, we could not establish a higher risk for a diagnosis of anxiety in these spouses.

The incidence of depression that we found is much lower than that reported in a review by Cuijpers et al.9 of depressive disorders in caregivers of dementia patients. Their estimatse that $48 \%$ of the caregivers develop depression was based on only one study of selective caregivers recruited from psychiatric services and memory clinics. In our study, we could make use of an unselected population derived from a large number of general practices and a long follow-up period. Unlike the findings of other studies, the incidences in our study were based on continuous recordings of diagnoses by GPs who received a training in recording and coding. The quality of the data recorded by the GPs was guaranteed in various ways, because the GPs participating in LINH have several facilities that make it easier for them to code the diagnoses according to the ICPC. The data were also checked for underreporting. 26

Given the lack of studies reporting on the incidence of anxiety in dementia caregivers, it is difficult to compare our findings with the results of earlier research. We found a slightly higher IR for anxiety in spouses than in the comparison group, but this difference was not statistically significant. Anxiety (comorbid) is often labeled as stress, or considered to be sufficiently covered by a diagnosis of depression only, rather than being defined as a separate affective state. 27 Therefore, it is possible that anxiety in 
Joling, K.J., Hout, H.P.J. van, Schellevis, F.G., Horst, H.E. van der, Scheltens, P., Marwijk, H.W.J. van_Uncidrence of depression and anxiety in the spouses of patients with dementia: a naturalistic cohort study of recorded morbidity with a 6-year follow-up. American Journal of Geriatric Psychiatry: 2010, 18(2), 146-153

spouses and comparison spouses could sometimes have been missed by the GPs due to the overlapping symptoms in anxiety and depression.

Our findings are an important addition to the existing literature, because so little is known about the incidence of depression and anxiety among the spouses of patients with dementia. We emphasize that our data reflect recorded and not population-based incidences of depression and anxiety in the spouses of patients with dementia and nondemented persons. This could be seen as a weakness in the study design because of possible underreporting by the GPs. However, as mentioned above, GPs were supported in using ICPC coding in several ways, and their registration systems checked for missing data and reminded the GP to code a diagnosis. Because of that, it is unlikely that a large number of persons with psychiatric problems were missed. Moreover, the comparison spouses were selected from the same practice as the spouses of the patients with dementia, so the quality of the registrations will be the same for the spouses and the comparison spouses.

One limitation of our study is that morbidity cannot be identified in persons who do not visit or who do not present specific symptoms to their GP. However, every person in the Netherlands is registered in a general practice, and the vast majority of older people visit their GP frequently. In our study population, only $4 \%$ of the spouses and $8 \%$ of the comparison spouses did not visit their GP at all.

Another limitation of our study is that we did not take into account any other chronic disease than dementia in the partners of the comparison spouse spouses. It is possible that the comparison spouses were caring for a relative with chronic health problems other than dementia. For that reason, we want to emphasize that the results we present do not concern differences between caregivers and noncaregivers but differences between the spouses of dementia patients and the spouses of nondemented persons.

In conclusion, our results show that the spouses of patients with dementia were more likely to be diagnosed with depression by their GP than the matched spouses of nondemented persons. We could not establish this for anxiety. These results indicate that professionals should pay attention to the high-risk group of spouses who are caregivers of patients with dementia.

\section{REFERENCES}

1. Hofman A, Rocca WA, Brayne C, et al: The prevalence of dementia in Europe: a collaborative study of 1980-1990 findings. Eurodem Prevalence Research Group. Int J Epidemiol 1991; 20: 736-748

2. Ory M, Yee JL, Tennstedt SL, et al: The extent and impact of dementia care: unique challenges experienced by family caregivers, in Handbook on Dementia Caregiving: Evidence-Based Interventions for Family Caregivers. Edited by Schulz R. New York, Springer, 2000, pp 1-32

3. National Alliance for Caregiving, AARP: Family Caregiving in the U.S.: Findings From a National Survey. Final Report. Bethesda, MD, National Alliance for Caregiving, 1997

4. Pinquart M, Sorensen S: Differences between caregivers and noncaregivers in psychological health and physical health: a metaanalysis. Psychol Aging 2003; 18:250-267

5. Martire LM, Hall M: Dementia caregiving: recent research on negative health effects and the efficacy of caregiver interventions. CNS Spectr 2002; 7:791-796

6. Schulz R, O'Brien AT, Bookwala J, et al: Psychiatric and physical morbidity effects of dementia caregiving: prevalence, correlates, and causes. Gerontologist 1995; 35:771-791

7. Coope B, Ballard CG, Saad K, et al: The prevalence of depression in the carers of dementia sufferers. Int J Geriatr Psychiatry 1995; 10:237-242

8. Baumgarten M, Battista RN, Infante-Rivard C, et al: The psychological and physical health of family members caring for an elderly person with dementia. J Clin Epidemiol 1992; 45:61-70

9. Cuijpers P: Depressive disorders in caregivers of dementia patients: a systematic review. Aging Ment Health 2005; 9:325-330

10. Russo J, Vitaliano pp, Brewer DD, et al: Psychiatric disorders in spouse caregivers of care recipients with Alzheimer's disease and matched controls: a diathesis-stress model of psychopathology. J Abnorm Psychol 1995; 104:197-204

11. Cooper C, Balamurali TB, Livingston G: A systematic review of the prevalence and covariates of anxiety in caregivers of people with dementia. Int Psychogeriatr 2007; 19:175-195

12. Mittelman MS, Haley WE, Clay OJ, et al: Improving caregiver well-being delays nursing home placement of patients with Alzheimer disease. Neurology 2006; 67:1592-1599

13. Schulz R, Visintainer $P$, Williamson GM: Psychiatric and physical morbidity effects of caregiving. J

Gerontol 1990; 45:181-191 
Joling, K.J., Hout, H.P.J. van, Schellevis, F.G., Horst, H.E. van der, Scheltens, P., Marwijk, H.W.J. van.Jncidence of depression and anxiety in the spouses of patients with dementia: a naturalistic cohort study of recorated morbidity with a 6-year follow-up. American Journal of Geriatric Psychiatry: 2010, 18(2), 146-153

14. Schulz R, Williamson GM: A 2-year longitudinal study of depression among Alzheimer's caregivers. Psychol Aging 1991; 6:569- 578

15. Ballard CG, Eastwood C, Gahir M, et al: A follow up study of depression in the carers of dementia sufferers. BMJ 1996; 312:947

16. Kiecolt-Glaser JK, Dura JR, Speicher CE, et al: Spousal caregivers of dementia victims: Iongitudinal changes in immunity and health. Psychosom Med 1991; 53:345-362

17. Bodnar JC, Kiecolt-Glaser JK: Caregiver depression after bereavement: chronic stress isn't over when it's over. Psychol Aging 1994; 9:372-380

18. Collins CE, Given BA, Given CW: Interventions with family caregivers of persons with Alzheimer's disease. Nurs Clin North Am 1994; 29:195-207

19. Cardol M, van Dijk L, de Jong JD, et al: Huisartsenzorg: wat doet de poortwachter? Tweede Nationale Studie naar ziekten en verrichtingen in de huisartspraktijk. (Second Dutch National Survey on General Practice: Care by the General Practitioner: What Does the Gatekeeper do?). Utrecht/Bilthoven, NIVEL/RIVM, 2004

20. Wood M, Lamberts H: International Classification of Primary Care: Prepared for the World Organisation of National Colleges, Academies and Academic Associations of General Practitioners/ Family Physicians (WONCA) by the ICPC Working Party. Oxford, Oxford University Press, 1987

21. Biermans MC, Verheij RA, de Bakker DH, et al: Estimating morbidity rates from electronic medical records in general practice. Evaluation of a grouping system. Methods Inf Med 2008; 47:98- 106

22. Biermans MC, Elbers GH, Verheij RA, et al: External validation of EPICON: a grouping system for estimating morbidity rates using electronic medical records. J Am Med Inform Assoc 2008; 15: 770-775

23. Linden MWvd, Westert GP, Bakker DHd, et al. Tweede Nationale Studie naar ziekten en verrichtingen in de huisartspraktijk. Klachten en aandoeningen in de bevolking en in de huisartspraktijk.

Utrecht/Bilthoven, NIVEL/RIVM, 2004

24. Gutierrez RG: Stata Corporation: Parametric frailty and shared frailty survival models. Stata J 2002; 2:22-44

25. Statistics Netherlands: Available at: http://www.cbs.nl/en-GB/ menu/methoden/toelichtingen/alfabet/c/chronic-disorders.htm. 2008. Accessed February 16, 2009

26. Verheij R, Brake JT, Abrahamse H, et al: Landelijke Informatienetwerk huisartsenzorg. Feiten en cijfers over huisartsenzorg in Nederland. Utrecht/Nijmegen, NIVEL/WOK, 2006

27. Flaskerud JH, Carter PA, Lee P: Distressing emotions in female caregivers of people with AIDS, agerelated dementias, and advanced-stage cancers. Perspect Psychiatr Care 2000; 36:121-130

\section{TABLES AND FIGURE}

\section{TABLE 1. Characteristics of the Spouses and Comparison Spouses}

\begin{tabular}{|c|c|c|}
\hline & $\begin{array}{l}\text { Spouses } \\
(\mathbf{n}=218)\end{array}$ & $\begin{array}{l}\text { Comparison } \\
\text { Spouses } \\
(\mathbf{n}=353)\end{array}$ \\
\hline Female, no. (\%) & $131(60.1)$ & $191(54.1)$ \\
\hline $\begin{array}{l}\text { Mean follow-up period (years) } \\
\text { from } 2001 \text { (SD) }\end{array}$ & $4.78(1.5)$ & 4.67 (1.6) \\
\hline $\begin{array}{l}\text { Mean number of chronic diseases } \\
\text { in first year after entry in study } \\
\text { (range) }\end{array}$ & $0.85(0-5)$ & $0.89(0-5)$ \\
\hline $\begin{array}{l}\text { Mean number of visits to the GP } \\
\text { per year (SD) }\end{array}$ & $7.7(7.9)$ & $7.6(9.7)$ \\
\hline
\end{tabular}


Joling, K.J., Hout, H.P.J. van, Schellevis, F.G., Horst, H.E. van der, Scheltens, P., Marwijk, H.W.J. van_Uncidtznce of depression and anxiety in the spouses of patients with dementia: a naturalistic cohort study of recorded morbidity with a 6-year follow-up. American Journal of Geriatric Psychiatry: 2010, 18(2), 146-153

\section{FIGURE 1. Flow Chart of Study Population and Dropouts}

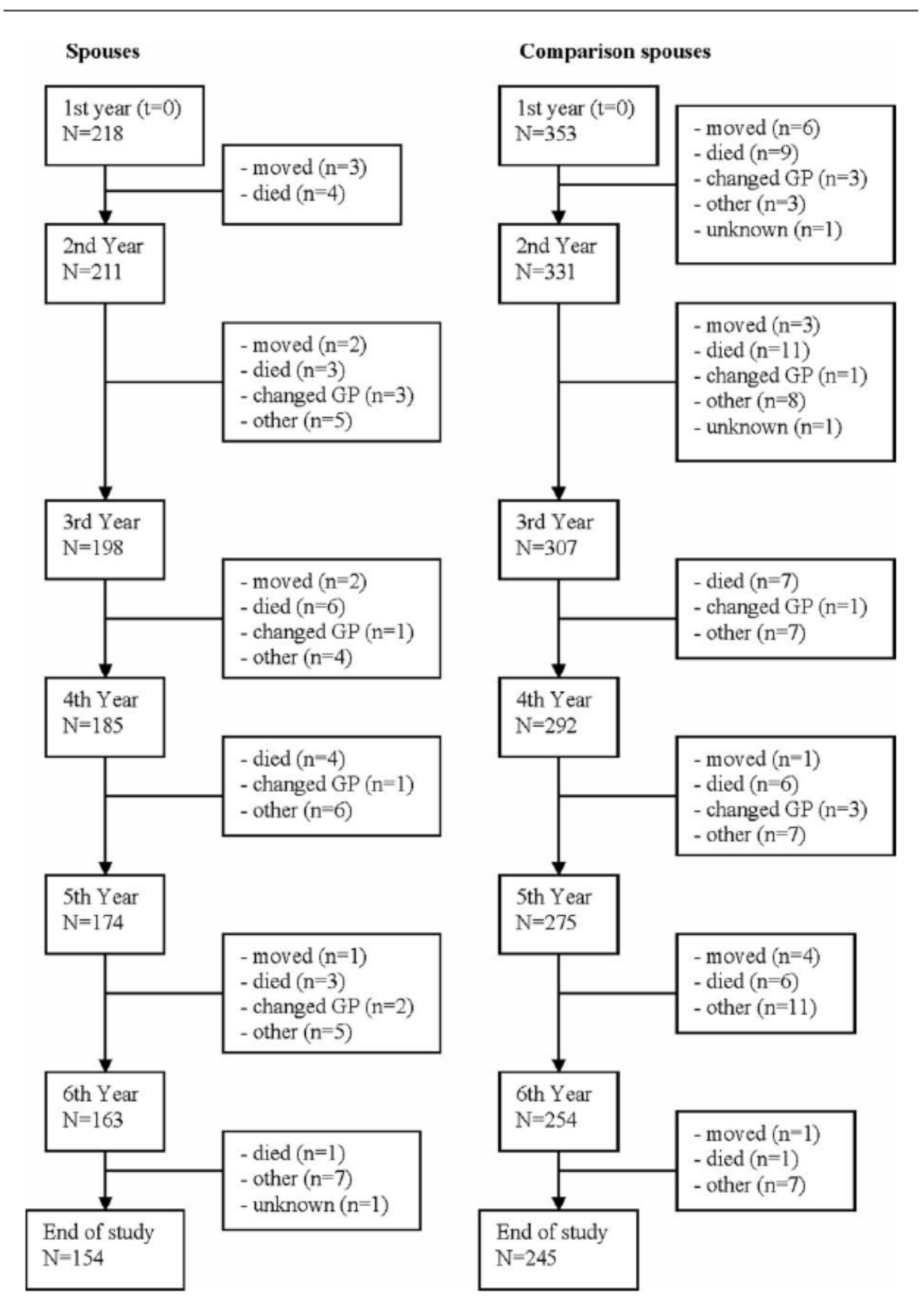


TABLE 2. Number of Persons With Depression and Anxiety and Prescriptions of Antidepressants and Anxiolytics Among Spouses and Comparison Spouses

\begin{tabular}{|c|c|c|}
\hline & \multicolumn{2}{|c|}{ Number } \\
\hline & $\begin{array}{c}\text { Spouses } \\
(\mathrm{n}=218)\end{array}$ & $\begin{array}{c}\text { Comparison } \\
\text { Spouses } \\
(\mathbf{n}=353)\end{array}$ \\
\hline Prevalent depression & 6 & 6 \\
\hline Incident depression (P76 or P03) & 18 & 7 \\
\hline Depressive disorder (P76) & 15 & 5 \\
\hline Depressive feelings (P03) & 3 & 2 \\
\hline Prevalent anxiety & 6 & 7 \\
\hline Incident anxiety (P74 or P01) & 12 & 15 \\
\hline Anxiety disorder (P74) & 2 & 3 \\
\hline Anxious feelings (P01) & 10 & 12 \\
\hline \multicolumn{3}{|l|}{ Prescriptions } \\
\hline Antidepressants (N06A) & 38 & 28 \\
\hline Anxiolytics (N05B) & 56 & 62 \\
\hline Antidepressants and anxiolytics & 18 & 10 \\
\hline
\end{tabular}

